\title{
Social Context and the Dynamics of Cooperative Choice
}

\author{
DAVID G. RAND ${ }^{1,2,3,4 *}$, GEORGE E. NEWMAN ${ }^{3,4}$ and OWEN M. WURZBACHER ${ }^{1}$ \\ ${ }^{1}$ Department of Psychology, Yale University, New Haven CT, USA \\ ${ }^{2}$ Department of Economics, Yale University, New Haven CT, USA \\ ${ }^{3}$ Program in Cognitive Science, Yale University, New Haven CT, USA \\ ${ }^{4}$ School of Management, Yale University, New Haven CT, USA
}

\begin{abstract}
Recent work using decontextualized economic games suggests that cooperation is a dynamic decision-making process: Automatic responses typically support cooperation on average, while deliberation leads to increased selfishness. Here, we performed two studies examining how these temporal effects generalize to games with richer social context cues. Study 1 found that time pressure increased cooperation to a similar extent in games played with in-group members and out-group members. Study 2 found that time pressure increased cooperation to a similar extent in games described as competitions and games described as collaborations. These results show that previous positive effects of time pressure on cooperation are not unique to neutrally framed games devoid of social context and are not driven by implicit assumptions of shared group membership or cooperative norms. In doing so, our findings provide further insight into the cognitive underpinnings of cooperative decision making. Copyright (C) 2014 John Wiley \& Sons, Ltd.
\end{abstract}

Additional supporting information may be found in the online version of this article at the publisher's web-site.

KEY WORDS cooperation; intuition; dual process; in-group bias; competition; framing; time pressure

Cooperative dilemmas pit the costs associated with sharing one's resources against the benefits that sharing creates for others. Given that cooperation is such an essential aspect of daily life (as well as a necessary condition for the continued survival of humankind), a great deal of research across psychology, economics, sociology, and biology has tried to understand and model how people make cooperation decisions (Apicella, Marlowe, Fowler, \& Christakis, 2012; Axelrod, 1984; Bazerman, Magliozzi, \& Neale, 1985; Bereby-Meyer \& Roth, 2006; Bicchieri \& Xiao, 2009; Crockett, 2009; Dawes, McTavish, \& Shaklee, 1977; DeSteno, 2009; Fiedler, Glöckner, Nicklisch, \& Dickert, 2013; Frank, Gilovich, \& Regan, 1993; Fudenberg \& Maskin, 1986; Fudenberg, Rand, \& Dreber, 2012; Galinsky \& Mussweiler, 2001; Gray, Ward, \& Norton, 2014; Halevy, Weisel, \& Bornstein, 2012; Locey \& Rachlin, 2012; Pfeiffer, Tran, Krumme, \& Rand, 2012; Rand \& Nowak, 2013; Sanfey, Rilling, Aronson, Nystrom, \& Cohen, 2003; Van den Bos, Vermunt, \& Wilke, 1997; Zaki \& Mitchell, 2011). Economic games have become a standard paradigm for exploring cooperation across fields because of their simple quantification of cooperativeness and their use of actual behavior rather than self-report measures or hypothetical scenarios (Camerer \& Fehr, 2002). In these games, participants are given money and make choices between allocations that benefit themselves or benefit others. In the public goods game, for example, players decide how much money to keep versus contribute to a public pot, the contents of which is multiplied by some factor and divided equally among all of members of their group. Thus, the tension between

*Correspondence to: David G. Rand, Department of Psychology, Yale University, 607-592-0218, 2 Hillhouse Ave, New Haven CT 06511, USA. E-mail: David.Rand@Yale.edu individual and collective interests, which is at the heart of social dilemmas, is captured in a single incentivized decision.

Here, we consider the cognitive dynamics of cooperation in these economic games. We do so using a dual-process perspective where decisions are conceptualized as resulting from the interaction between two different types of cognitive processes (Chaiken \& Trope, 1999; Frederick, 2005; Kahneman, 2003, 2011; Miller \& Cohen, 2001; Sloman, 1996; Stanovich \& West, 1998): those that are fast, automatic, and intuitive and those that are slow, controlled, and reflective. How, then, do self-interested and other-regarding motivations map onto these different types of decision making? Is self-interest automatic, with cooperation requiring deliberation? Or, are first responses cooperative, with reflection leading toward selfishness?

To shed light on this question, we focus on the effects of applying time constraints to economic game decisions. Time constraints are widely used in experimental psychology as a tool for investigating the role of intuition versus deliberation in decision making (Evans \& Curtis-Holmes, 2005; Kahneman, 2011; Roberts \& Newton, 2001; Suter \& Hertwig, 2011; Wright, 1974). A key property of intuitive processing is that it is automatic and operates relatively quickly, whereas deliberative processing is typically slower and involves overriding automatic responses. Therefore, forcing people to decide quickly reduces their ability to reflect and gives them less opportunity to override their intuitive responses. Conversely, forcing people to stop and think has the opposite effect, allowing for more deliberation. Of course, the application of time pressure does not result in purely intuitive responding, nor does the enforcement of a delay result in purely reflective responding. Reflection may fail to override deeply held intuitions, and some subjects may engage in substantial reflection even under time pressure. Rather, by comparing time pressure and time 
delay, we can reveal the dominant directions of the effects of intuitive versus reflective processing.

Recent studies applying time constraints to economic games suggest that cooperative decision making is an inherently dynamic process: Time pressure sometimes increases cooperation in these games and sometimes has no effect but has not been found to systematically decrease cooperation (Rand, Greene, \& Nowak, 2012; Rand \& Kraft-Todd 2014; Rand et al., 2014; Tinghög et al., 2013). This pattern of results suggests that, on average, time pressure favors cooperation in economic games but that this effect is subject to various moderators. ${ }^{1}$

To explain this pattern of results, and to predict specific moderators, we have suggested the "social heuristics hypothesis" (SHH; Rand et al., 2014). The SHH posits that strategies that are advantageous (i.e., payoff maximizing) in daily life interactions become automatized as intuitions and get overgeneralized to less typical settings. The SHH therefore predicts that experiences outside the lab should moderate automatic responses (e.g., cooperation should be the default for people whose daily life interaction partners are trustworthy and who thus make cooperation profitable, but not for those who experience the world as untrustworthy). Consistent with this prediction, trust of daily life interaction partners has been shown to moderate the correlation between decision time and cooperation (Rand et al., 2012), as well as the effect of a time pressure manipulation (Rand \& Kraft-Todd 2014). Additionally, the SHH predicts that prior exposure to lab paradigms should undermine the overgeneralization that drives automatic cooperation by giving participants a chance to develop new defaults for these games (or learn not to trust their intuitions in these settings). Consistent with this second prediction, selfreported level of previous experience with economic games moderates the effect of time pressure on cooperation (Rand \& Kraft-Todd 2014; Rand et al., 2014), and a longitudinal analysis shows the remodeling of time-pressured responses over 2 years as economic game experiments became increasingly common in a particular subject pool (Rand et al., 2014). Finally, direct support for the $\mathrm{SHH}$ comes from experiments where participants are immersed in laboratory environments that favor either cooperation or noncooperation, establishing behavioral patterns that spill over into subsequent one-shot anonymous

\footnotetext{
${ }^{1}$ Although time constraints are our main focus, we note that a similar range of positive to null, but not negative, effects has been found when applying cognitive load (Cornelissen, Dewitte \& Warlop, 2011; Hauge, Brekke, Johansson, Johansson-Stenman \& Svedsäter, 2009; Roch, Lane, Samuelson, Allison \& Dent, 2000; Schulz, Fischbacher, Thöni \& Utikal, 2014) or conceptual priming of intuition versus reflection (Kinnunen \& Windmann, 2013; Rand et al., 2012) to economic cooperation games and that impairing the function of the right lateral prefrontal cortex, a brain region associated with deliberation and control, increases giving in a unilateral money transfer, while amplifying this region decreases giving (Ruff, Ugazio \& Fehr, 2013). Results using ego depletion have been more mixed (Balliet \& Joireman, 2010; Halali, Bereby-Meyer \& Meiran, 2014; Halali, Bereby-Meyer \& Ockenfels, 2013), suggesting that ego depletion may manipulate more than just cognitive style. So too have experiments examining unethical behavior such as lying or cheating (e.g., Foerster, Pfister, Schmidts, Dignath \& Kunde, 2013; Greene \& Paxton, 2009; Gunia, Wang, Huang, Wang \& Murnighan, 2012; Mead, Baumeister, Gino, Schweitzer \& Ariely, 2009; Pitesa, Thau \& Pillutla, 2013; Shalvi, Eldar \& Bereby-Meyer, 2012), suggesting that the motivations in these settings may be more complex than the fairly unambiguous prosociality in economic games.
}

interactions, but only among subjects who rely on heuristics (Peysakhovich \& Rand, 2013).

A separate line of research suggests that cooperation levels in economic games can be influenced by subtle changes in social context. For example, changing the name of an identical prisoner's dilemma payoff structure from the "community game" to the "wall street game" can substantially reduce cooperation (Dreber, Ellingsen, Johannesson \& Rand, 2013; Liberman, Samuels \& Ross, 2004). Similarly, describing the game as a competition reduces cooperation related to a neutrally framed baseline or a game described as a collaboration (Engel \& Rand, 2014). Framing the cooperative decision as a "contribution to a public good" versus "extraction from a common resource" also effects cooperation levels (Brewer \& Kramer, 1986; Fleishman, 1988) and priming the concept of money reducing helping (Vohs, Mead \& Goode, 2006).

In addition to this type of cue regarding the social environment, information about one's interaction partner(s) also influences cooperation. For example, people are more prosocial toward those with whom they are more similar, such as sharing incidental similarities like birthdays or first names (Burger, Messian, Patel, del Prado \& Anderson, 2004) or being members of the same group (Dunham, Baron \& Banaji, 2008). The latter is true both for membership in trivial groups, such as those preferring the paintings of Klee or Kandinsky (Tajfel, Billig \& Flament, 1971; Yamagishi \& Mifune, 2008), and for more meaningful groupings, such as political affiliation (Fowler \& Kam, 2007; Rand et al., 2009) or ethnicity (Whitt \& Wilson, 2007).

This susceptibility of cooperative decision making to social context raises interesting questions regarding previous results on time pressure in economic games. Were these earlier findings the result of participants implicitly assuming that partners in the game were in-group members or that the game was one where cooperation was expected of them? More generally, will time pressure continue to favor cooperation in social contexts that are unfriendly to cooperation (i.e., where overall cooperation rates are lower)? Here, we address these questions by crossing a time constraint manipulation with two different manipulations of social context. Study 1 examines the effect of group membership on the dynamics of cooperation by comparing games played between supporters of the same versus different presidential candidates on the day of the 2012 US presidential election. Study 2 compares the cooperative dynamics of a game described as a collaboration versus a competition.

\section{STUDY 1}

\section{Method}

\section{Participants}

Two hundred three participants residing in the USA $(51 \%$ female subjects, mean age 33.6 years) were recruited for Study 1 using Amazon Mechanical Turk (MTurk) (Amir, Rand \& Gal, 2012; Buhrmester, Kwang \& Gosling, 2011; Horton, Rand \& Zeckhauser, 2011; Paolacci, Chandler \& Ipeirotis, 2010; Rand, 2012). Participants were paid a $\$ 0.50$ showup for completing the study and could earn up to an additional 
$\$ 1.20$ depending on decisions made during the study. To maximize the salience of group identity based on political orientation, the study was conducted on November 6, 2012, the date of the 2012 US presidential election.

\section{Procedure and materials}

Cooperation measure. To measure participants' level of cooperation, we used a one-shot continuous prisoner's dilemma game. Each participant chose how much of a $\$ 0.40$ endowment to keep for themselves and how much to transfer to their partner. They were informed that any money transferred would be doubled by the experimenter, that their partner would simultaneously be making the same decision, and that they would only play the game once. To make the payoff structure clear, several examples were given and the participants were explicitly reminded that they would maximize their earnings by transferring nothing (no matter what their partner chose to do). We added this reminder because in previous work on MTurk, we found that while most participants understood that transferring the maximum amount was best for the other person, many participants were confused about which option was best for them individually (incorrectly believing that cooperating also maximized their own payoff). We take the amount of money transferred as our measure of cooperation.

Group membership manipulation. To experimentally manipulate perceptions of shared group membership, we created pairs of participant that supported either the same candidate or different candidates in the 2012 US presidential election. Prior to reading the prisoner's dilemma instructions, participants began the study by indicating which candidate they preferred, Barack Obama or Mitt Romney (70.9\% of participants preferred Barack Obama). They were then told that they had been randomly assigned to interact with another worker from MTurk, informed of their partner's preferred candidate, and told about the payoff structure of the game (following the procedure of previous work on shared political affiliation and prosociality (Rand et al., 2009)).

Time constraint manipulation. To experimentally manipulate the dynamics of cooperative decision making, we imposed a time constraint on participants. After reading through the instructions at their own pace, participants were taken to a new page where they indicated how many cents to transfer to their partner (using a radio button with options for 0,10 , 20, 30, or 40; no default selection). In the time pressure condition, participants were asked on this screen to decide as quickly as possible and told that they must decide within 10 seconds (a timer counted seconds down from 10). In the time delay condition, participants were asked on this screen to carefully consider their decision and told that they must stop and think for at least 10 seconds before deciding (a timer counted seconds up from 0). Participants who did not obey the time constraint were still allowed to make a decision (under time pressure, $6.5 \%$ of participants took more than 10 seconds; under time delay, $17.5 \%$ of participants decided in less than 10 seconds). The median decision time was 6 seconds in the time pressure condition and 15 seconds in the time delay condition. We included all participants in our analysis regardless of whether they obeyed the time constraint (although as we note in the succeeding texts, excluding participants who disobeyed the time constraint does not qualitatively change our results).

Comprehension. After making their decision, participants were taken to a new screen where their comprehension of the game structure was assessed. We did so by asking participants two qualitative questions regarding the payoff structure, as in previous work (Rand et al., 2012): "What amount would you give in order to maximize the other person's earnings?" and "What amount would you give in order to maximize your earnings?" These questions were designed to test whether participants understood that they were facing a social dilemma where their interests ran counter to the other person's interests. A total of $32 \%$ of participants answered one or both questions incorrectly $(14 \%$ answered the first question incorrectly, and $30 \%$ answered the second question incorrectly). In line with standard practice on MTurk, participants were told that they had to answer both correctly in order to receive their earnings from the game. Once decisions had been collected from all participants, they were paired as described and paid accordingly (except for participants that failed the comprehension check, who received only the showup fee). The comprehension questions were placed after the decision, rather than before, because of evidence that answering comprehension questions can itself induce a reflective mindset (Rand et al., 2012), and we did not want to undermine the effect of our time pressure manipulation.

Screenshots of the experimental materials are included in Appendix A in Supplementary Information.

\section{Results and discussion}

The average fraction of the endowment transferred is shown by condition in Figure 1. Examining main effects, participants transferred $24 \%$ more under timer pressure than time delay ( 25.8 cents vs 20.7 cents) and $19 \%$ more to supporters of the same candidate than to supporters of the other candidate (25.5 cents vs 21.3 cents). An ANOVA revealed significant main effects of time constraint $(F(1,195)=4.00$,

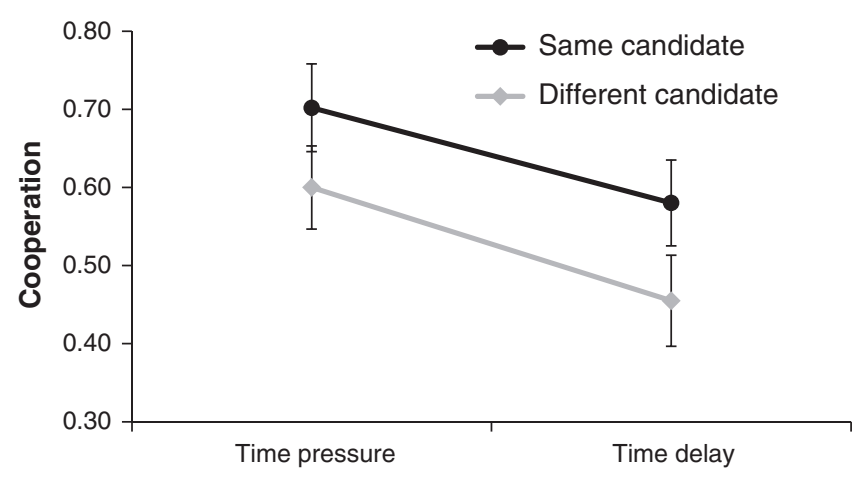

Figure 1. Average cooperation (fraction of endowment transferred to partner) in Study 1, by time constraint and group membership. Error bars indicate standard errors of the mean 
$p<0.05$; partial $\left.\eta^{2}=0.020\right)$ and shared group membership $\left(F(1,195)=4.91, p<0.05\right.$; partial $\left.\eta^{2}=0.025\right)$ but no significant interaction between the two $(F(1,195)=0.05, p=0.83)$, as well as a significant positive effect of failing the comprehension questions $(F(1,195)=4.08, \quad p<0.05$; partial $\left.\eta^{2}=0.021\right)$ and no significant effects of age, gender, or preferred candidate. We note that the significant main effects of time constraint and group membership serve as manipulation checks, showing that we successfully increased cooperation through time pressure and decreased cooperation through pairing with an out-group member, as predicted based on past research. We also note that excluding the participants who disobeyed the time constraint does not qualitatively change our results: Doing so, we find a significant main effect of time constraint $(F(1,171)=4.07, p<0.05$; partial $\left.\eta^{2}=0.023\right)$, a marginally significant main effect of shared group membership $(F(1,171)=3.14, \quad p<0.08$; partial $\left.\eta^{2}=0.018\right)$, and no significant interaction between the two $(F(1,171)=0.24, p=0.63)$, as well as no significant effects of comprehension, age, gender, or preferred candidate.

It is possible that the relationship between time constraint and shared group membership differed between supporters of Romney versus Obama. However, we did not have enough participants that preferred Romney to conduct a meaningful analysis of their behavior (15 participants per condition on average). If we restrict to supporters of Obama, we observe qualitatively similar results to our main analysis: significant main effects of time constraint $(F(1,139)=4.41, p<0.05$; partial $\left.\eta^{2}=0.031\right)$ and shared group membership $(F(1,139)=5.10$, $p<0.05$; partial $\left.\eta^{2}=0.035\right)$, but no significant interaction between the two $(F(1,139)=1.91, p=0.17)$, as well as a marginally significant positive effect of failing the comprehension questions $\left(F(1,139)=3.60, p<0.06\right.$; partial $\left.\eta^{2}=0.025\right)$ and no significant effects of age or gender. We note that to the extent that the interaction between time constraint and shared group membership is trending here, it is trending in the opposite direction of what might have been expected: Among Obama supporters, there is a significant positive simple effect of time pressure with out-group members $(F(1,139)=5.93, p<0.05)$ but not in-group members $(F(1,139)=0.27, p=0.60)$.

In sum, the results of Study 1 provide evidence that a social context involving group membership based on political affiliation does not moderate the effect of time pressure. The lack of significant interaction between time constraint and group membership suggests that the in-group/out-group context does not fundamentally alter the dynamics of cooperation. Instead, we seem to observe an anchoring effect. When interacting with out-group members, participants' default responses are less cooperative than when interacting with in-group members. In both cases, further deliberation then adjusts cooperation downward toward self-interest.

\section{STUDY 2}

In Study 2, we sought to replicate the results of Study 1 using a second social context that is known to effect cooperation. Previous work has demonstrated that describing games using language that suggests a norm of competition decreases cooperation (Dreber et al., 2013; Engel \& Rand, 2014; Liberman et al., 2004). Thus, we compared behavior in a public goods game described as choosing how much to contribute to a common project (the standard language used in many public goods game studies, for example, (Fehr \& Gächter, 2000)) with a game described as a competition between the group members. We also shifted to studying cooperation in a four-person group social dilemma, rather than the pairwise dilemma used in Study 1.

\section{Method \\ Participants}

Nine hundred one participants residing in the USA (46\% female subjects, mean age 31.3 years) were recruited for Study 2 using MTurk. Participants were paid a $\$ 0.50$ showup for completing the study and could earn up to an additional $\$ 1.00$ depending on decisions made during the study.

\section{Procedure and materials}

Cooperation measure. To measure participants' level of cooperation, we used a one-shot four-player public goods game (a multiplayer analog of the continuous prisoner's dilemma). We followed the same procedure as in prior work (Rand et al., 2012): Each participant chose how much of a $\$ 0.40$ endowment to keep for themselves and how much (if any) to contribute. Any money contributed was doubled by the experimenter and split evenly among the four group members. The game was only played once, and the participants were informed of this. To make the payoff structure clear, several examples were given and the participants were explicitly reminded that they would maximize their earnings by transferring nothing (no matter what the other group members chose to do). We take the amount of money contributed as our measure of cooperation.

Competitive context manipulation. To experimentally manipulate perceptions of the competitiveness of the interaction environment, the wording of the instructions was altered. In the collaboration condition, the game was described as choosing how much to contribute to a common project, and the other group members were described using neutral language. In the competition condition, participants were informed that they were competing against three opponents and that the person who earned the most would beat the others and be notified that he or she was the winner. As a manipulation check, participants were asked a postexperimental question about how competitive they felt toward the other group members (using a seven-point Likert scale). As predicted, participants reported feeling more competitive in the competition condition: An ANOVA showed a significant main effect of context on competitiveness $(F(1,741)=4.01, p<0.05)$, no significant main effect of time constraint, no interaction between the two, and no significant effect of age, gender, or failing the comprehension questions.

Time constraint manipulation. To experimentally manipulate the dynamics of our participants' cooperative decision making, we used the time constraint implementation introduced 
in (Rand et al., 2012). After completing the instructions, participants were taken to a new page where they indicated how many cents to contribute (using a slider initialized at $50 \%$, as in prior public goods game experiments (Rand et al., 2012)). In the time pressure condition, participants were asked to decide as quickly as possible and told that they must decide within 10 seconds; in the time delay condition, participants were asked to carefully consider their decision and told that they must stop and think for at least 10 seconds before deciding. Unlike Study 1, no timers were presented to participants. The median decision time was 8 seconds in the time pressure condition and 23 seconds in the time delay condition. Under time pressure, $24 \%$ of participants took more than $10 \mathrm{sec}$ onds; under time delay, $10 \%$ of participants decided in less than 10 seconds. Thus, because of the lack of timers in Study 2 , substantially more participants disobeyed the time pressure constraint than in Study 1 (6.5\% in Study 1 vs 24\% in Study 2), necessitating the exclusion of noncomplaint subjects. However as noted below, our key finding (a positive effect of time pressure under the competitive frame), is robust to including subjects that disobeyed the time constraint.

Comprehension. After making their decisions, participants were taken to a new screen with similar comprehension questions to those used in Study 1: "What level of contribution earns the highest payoff for the group as a whole?" and "What level of contribution earns the highest payoff for you personally?" A total of $23 \%$ of participants answered one or both questions incorrectly $(6 \%$ answered the first question incorrectly, and $22 \%$ answered the second question incorrectly). Once decisions had been collected from all participants, they were grouped in fours as described and paid accordingly (except for participants failing the comprehension questions, who received only the showup fee).

Screenshots of the experimental materials are included in Appendix B in Supplementary Information.

\section{Results and discussion}

The average fraction of the endowment contributed is shown by condition in Figure 2. Examining main effects, participants transferred $10 \%$ more under timer pressure than under time delay ( 25.5 cents vs 23.2 cents) and $12 \%$ more in the collaboration condition than in the competition condition (25.6 cents vs 22.8 cents). An ANOVA revealed significant main effects of time constraint $(F(1,737)=4.28, p<0.05$; partial $\left.\eta^{2}=0.006\right)$ and competitive context $(F(1,737)=4.97$, $p<0.05$; partial $\left.\eta^{2}=0.007\right)$, but no significant interaction between the two $(F(1,737)=0.87, p=0.35)$, as well as a significant positive effect of age $(F(1,737)=9.07, p<0.005$; partial $\eta^{2}=0.012$ ), a marginally significant negative effect of failing the comprehension questions $(F(1,737)=3.73$, $p=0.054$; partial $\left.\eta^{2}=0.005\right)$, and no significant effect of gender.

Although the interaction between time constraint and competitive context is far from statistical significance, the sign of the interaction is noteworthy: Time pressure had a somewhat bigger positive effect on cooperation in the competition condition than in the collaboration condition. Indeed,

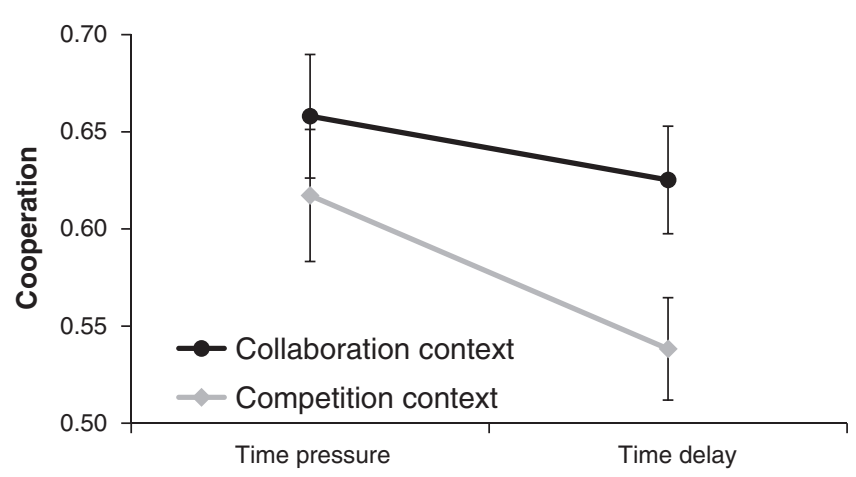

Figure 2. Average cooperation (fraction of endowment contributed to public good) in Study 2, by time constraint and competitive social context. Error bars indicate standard errors of the mean

we observe a significant positive simple effect of time pressure in the competition condition $(F(1,737)=4.38, p<0.05$; including subjects who did not obey the time constraint: $\mathrm{F}(1,894)=3.91, \mathrm{p}<0.05)$ but no significant simple effect in the collaboration condition $(F(1,737)=0.67, p=0.41$; in cluding subjects who did not obey the time constraint: $F$ $(1,894)=0.10, p=0.76)$. This lack of time pressure effect in the collaboration condition is surprising given prior work (Rand et al., 2012) and may be the result of the MTurk subject pool's increasing familiarity with the standard (collaboration based) public goods game design. Such familiarity has been shown to undermine the effect of time pressure on cooperation (Rand \& Kraft-Todd 2014; Rand et al., 2014). The significant time pressure effect in the Competition condition, even when including subjects who failed to obey the time constraint, however clearly demonstrates that applying time pressure can increase cooperation in competitively framed interactions.

In sum, the lack of significant interaction between time constraint and group membership, together with both significant main effects, replicated the results of Study 1. We again found that social context, this time the level of competitiveness, did not fundamentally change the dynamics of cooperation. Thus, we provide additional evidence for a time pressure effect that can operate independently of social context. In addition, this study demonstrated that the results of Study 1 replicate in a group cooperative dilemma (using four rather than two individuals).

\section{GENERAL DISCUSSION}

The present studies find little evidence that two often-studied social context manipulations change the dynamics of cooperative decision making in economic games. Responses made under time pressure were more cooperative than reflective responses, even when making decisions regarding out-group members or in competitive settings. Thus, rather than social context fundamentally altering the dynamics of cooperation, context may instead serve as an initial anchor for intuitive cooperation levels that are then reduced as individuals deliberate. 
These results have important implications for understanding the cognitive underpinnings of cooperation. Our findings suggest that the positive effect of time pressure on cooperation in economic games generalizes further than previously known. The fact that time pressure promotes cooperation even with out-group members and in competitive settings provides evidence that previously reported effects (e.g., Rand et al., 2012; Rand \& Kraft-Todd 2014; Rand et al., 2014) are not artifacts of participants implicitly assuming that their partners were in-group members or presuming that they were interacting in a situation where cooperation was the prescribed norm. The robustness to context that we observe here is also consistent with the recent finding that time pressure promotes cooperation in a public goods game framed as conservation (i.e., not extracting a resource) rather than contribution (Rand et al., 2014).

In future work, it may be interesting to examine situations where social context may indeed interact with time pressure/delay. Such effects could arise in situations where people hold explicit beliefs about failing to appear cooperative. For example, when interacting with members of a different racial group, time delay may actually result in more cooperation as individuals may wish to avoid being perceived as (or feeling) racially biased. Given the present findings, however, such an interaction would not imply that cooperation under time pressure is unique to in-group members. Rather, it would suggest that multiple countervailing but independent effects of increasing cognitive reflection were in action simultaneously, one where reflection undermines cooperation and the other where reflection counters racial bias.

While the effects of time pressure and social context that we find are statistically significant, the size of these effects bears comment. The partial $\eta^{2}$ s are quite small, suggesting that our manipulations each explain less than $5 \%$ of the variation in cooperation in Study 1 and less than $1 \%$ of the variation in cooperation in Study 2. Nevertheless, the actual magnitudes of the effects (rather than the fraction of variance explained) are not insubstantial, with manipulations increasing the amount of money spent on cooperation by between 10 and $24 \%$, depending on the study and condition. These effect sizes are in line with previous work: A recent meta-analysis of 15 experiments applying time pressure to economic cooperation games found an average of $21.5 \%$ increase in cooperation under time pressure compared with time delay, with a partial $\eta^{2}$ of 0.007 (Rand et al., 2014; we also note that similar time pressure effect sizes were found using \$0.40 stakes on MTurk and \$4.00 stakes in the lab (Rand et al., 2012), suggesting at least some invariance to stake size.) Thus, although the partial $\eta^{2}$ s are small and many different factors beyond our manipulations determine cooperative behavior, our effects are nonetheless of potential economic and practical importance.

Furthermore, our time constraint manipulation does not fully separate participants' decision making into intuitive or deliberative. Some participants under time pressure may still have engaged in varying degrees of deliberation within 10 seconds, and some participants under time delay may have stuck with their default response to varying degrees even after 10 seconds of consideration. Thus, our effect sizes should be seen as lower bounds.

It is important to note that the nonsignificant interactions that we observe between time constraint and social context are null effects. Thus, the fact that we do not find significant interactions does not necessarily mean that no such interactions exist. However, the sign of these nonsignificant interactions is informative: In both studies, the trend is for time pressure to have a larger positive effect on cooperation in the context that is less favorable to cooperation overall (out-group context in Study 1 and competitive context in Study 2). These findings add further evidence that positive effects of time pressure on cooperation are not limited to settings that prescribe cooperative behavior.

In sum, the current studies suggest that time pressure promotes cooperation in economic cooperation games and that this effect extends even to two social contexts that are "hostile" toward cooperation. Rather than changing the dynamics of cooperative decision making, the social contexts that we examined appear to provide an anchor for automatic responses. These results suggest that social context effects may enter the cooperative decision making process at a very early stage and are already firmly in place before deliberation begins to undermine cooperative defaults. In other words, the dynamic nature of cooperative decision making may be relatively encapsulated from top-down influences. This is important because it suggests that other types of contextual factors (e.g., the presence of numerical anchors, changes in mood, feeling more powerful than one's partner, etc.) may influence cooperative decision making at a stage that is prior to, and distinct from, subsequent effects of deliberation. Although future work is, of course, needed to establish whether this model generalizes more broadly across social contexts, the current studies provide initial support for that possibility.

\section{REFERENCES}

Amir, O., Rand, D. G., \& Gal, Y. K. (2012). Economic Games on the Internet: The Effect of $\$ 1$ Stakes. PLoS ONE, 7(2), e31461. doi: 10.1371/journal.pone.0031461

Apicella, C. L., Marlowe, F. W., Fowler, J. H., \& Christakis, N. A. (2012). Social networks and cooperation in hunter-gatherers. Nature, 481(7382), 497-501.

Axelrod, R. (1984). The Evolution of Cooperation. New York: Basic Books.

Balliet, D., \& Joireman, J. (2010). Ego depletion reduces proselfs' concern with the well-being of others. Group Processes \& Intergroup Relations, 13(2), 227-239. doi: 10.1177/ 1368430209353634

Bazerman, M. H., Magliozzi, T., \& Neale, M. A. (1985). Integrative bargaining in a competitive market. Organizational Behavior and Human Decision Processes, 35(3), 294-313. doi: 10.1016/ 0749-5978(85)90026-3

Bereby-Meyer, Y., \& Roth, A. E. (2006). The speed of learning in noisy games: partial reinforcement and the sustainability of cooperation. The American Economic Review, 96(4), 1029-1042.

Bicchieri, C., \& Xiao, E. (2009). Do the right thing: but only if others do so. Journal of Behavioral Decision Making, 22(2), 191-208. doi: 10.1002/bdm.621

Brewer, M. B., \& Kramer, R. M. (1986). Choice behavior in social dilemmas: Effects of social identity, group size, and decision 
framing. Journal of Personality and Social Psychology, 50(3), 543-549. doi: 10.1037/0022-3514.50.3.543

Buhrmester, M. D., Kwang, T., \& Gosling, S. D. (2011). Amazon's Mechanical Turk: A New Source of Inexpensive, Yet HighQuality, Data? Perspectives on Psychological Science, 6(1), 3-5.

Burger, J. M., Messian, N., Patel, S., del Prado, A., \& Anderson, C. (2004). What a Coincidence! The Effects of Incidental Similarity on Compliance. Personality and Social Psychology Bulletin, 30(1), 35-43.

Camerer, C. F., \& Fehr, E. (2002). Measuring social norms and preferences using experimental games: A guide for social scientists.

Chaiken, S., \& Trope, Y. (1999). Dual-process theories in social psychology. New York: Guilford Press.

Cornelissen, G., Dewitte, S., \& Warlop, L. (2011). Are Social Value Orientations Expressed Automatically? Decision Making in the Dictator Game. Personality and Social Psychology Bulletin, 37(8), 1080-1090.

Crockett, M. J. (2009). The neurochemistry of fairness. Annals of the New York Academy of Sciences, 1167(1), 76-86.

Dawes, R. M., McTavish, J., \& Shaklee, H. (1977). Behavior, communication, and assumptions about other people's behavior in a commons dilemma situation. Journal of Personality and Social Psychology, 35(1), 1.

DeSteno, D. (2009). Social Emotions and Intertemporal Choice "Hot" Mechanisms for Building Social and Economic Capital. Current Directions in Psychological Science, 18(5), 280-284.

Dreber, A., Ellingsen, T., Johannesson, M., \& Rand, D. G. (2013). Do people care about social context? Framing effects in dictator games. Experimental Economics, 16(3), 349-371. doi: 10.1007/ s10683-012-9341-9

Dunham, Y., Baron, A. S., \& Banaji, M. R. (2008). The development of implicit intergroup cognition. Trends in Cognitive Sciences, 12(7), 248-253. doi: 10.1016/j.tics.2008.04.006

Engel, C., \& Rand, D. G. (2014). What does "clean" really mean? The implicit framing of decontextualized experiments. Economics Letters, 122(3), 386-389. doi: 10.1016/j.econlet.2013.12.020

Evans, J. S. B., \& Curtis-Holmes, J. (2005). Rapid responding increases belief bias: Evidence for the dual-process theory of reasoning. Thinking \& Reasoning, 11(4), 382-389.

Fehr, E., \& Gächter, S. (2000). Cooperation and punishment in public goods experiments. American Economic Review, 90, 980-994.

Fiedler, S., Glöckner, A., Nicklisch, A., \& Dickert, S. (2013). Social Value Orientation and information search in social dilemmas: An eye-tracking analysis. Organizational Behavior and Human Decision Processes, 120(2), 272-284.

Fleishman, J. A. (1988). The Effects of Decision Framing and Others' Behavior on Cooperation in a Social Dilemma. Journal of Conflict Resolution, 32(1), 162-180. doi: 10.1177/ 0022002788032001008

Foerster, A., Pfister, R., Schmidts, C., Dignath, D., \& Kunde, W. (2013). Honesty saves time (and justifications). Frontiers in psychology, 4: 473.

Fowler, J. H., \& Kam, C. D. (2007). Beyond the Self: Social Identity, Altruism, and Political Participation. Journal of Politics, 69(3), 813-827.

Frank, R. H., Gilovich, T., \& Regan, D. T. (1993). The evolution of one-shot cooperation: An experiment. Ethology and sociobiology, 14(4), 247-256.

Frederick, S. (2005). Cognitive Reflection and Decision Making. The Journal of Economic Perspectives, 19(4), 25-42.

Fudenberg, D., \& Maskin, E. S. (1986). The Folk Theorem in Repeated Games with Discounting or with Incomplete Information. Econometrica, 54(3), 533-554.

Fudenberg, D., Rand, D. G., \& Dreber, A. (2012). Slow to Anger and Fast to Forgive: Cooperation in an Uncertain World. American Economic Review, 102(2), 720-749.

Galinsky, A. D., \& Mussweiler, T. (2001). First offers as anchors: The role of perspective-taking and negotiator focus. Journal of
Personality and Social Psychology, 81(4), 657-669. doi: 10.1037/0022-3514.81.4.657

Gray, K., Ward, A. F., \& Norton, M. I. (2014). Paying It Forward: Generalized Reciprocity and the Limits of Generosity. Journal of experimental psychology: General, 143(1), 247-254.

Greene, J. D., \& Paxton, J. M. (2009). Patterns of neural activity associated with honest and dishonest moral decisions. Proceedings of the National Academy of Sciences, 106(30), 12506-12511.

Gunia, B. C., Wang, L., Huang, L., Wang, J., \& Murnighan, J. K. (2012). Contemplation and conversation: Subbtle influences on moral decision making. Academy of Management Journal, 55(1), 13-33.

Halali, E., Bereby-Meyer, Y., \& Meiran, N. (2014). Between SelfInterest and Reciprocity: The Social Bright Side of SelfControl Failure. Journal of experimental psychology: General, 143(2), 745-754.

Halali, E., Bereby-Meyer, Y., \& Ockenfels, A. (2013). Is it all about the self? The effect of self-control depletion on ultimatum game proposers. Frontiers in human neuroscience, 7, 240.

Halevy, N., Weisel, O., \& Bornstein, G. (2012). "In-Group Love" and "Out-Group Hate" in Repeated Interaction Between Groups. Journal of Behavioral Decision Making, 25(2), 188-195. doi: 10.1002/bdm.726

Hauge, K. E., Brekke, K. A., Johansson, L.-O., Johansson-Stenman, O., \& Svedsäter, H. (2009). Are Social Preferences Skin Deep? Dictators under Cognitive Load. University of Gothenburg Working Papers in Economics, (371).

Horton, J. J., Rand, D. G., \& Zeckhauser, R. J. (2011). The Online Laboratory: Conducting Experiments in a Real Labor Market. Experimental Economics, 14(3), 399-425. doi: 10.1007/ s10683-011-9273-9

Kahneman, D. (2003). A perspective on judgment and choice: Mapping bounded rationality. American Psychologist, 58(9), 697-720.

Kahneman, D. (2011). Thinking, Fast and Slow. New York, NY: Farrar, Straus and Giroux.

Kinnunen, S. P., \& Windmann, S. (2013). Dual-processing altruism. Frontiers in psychology, 4, 1-8.

Liberman, V., Samuels, S. M., \& Ross, L. (2004). The Name of the Game: Predictive Power of Reputations versus Situational Labels in Determining Prisoner's Dilemma Game Moves. Personality and Social Psychology Bulletin, 30(9), 1175-1185. doi: $10.1177 / 0146167204264004$

Locey, M. L., \& Rachlin, H. (2012). Temporal Dynamics of Cooperation. Journal of Behavioral Decision Making, 25(3), 257-263. doi: 10.1002/bdm.729

Mead, N. L., Baumeister, R. F., Gino, F., Schweitzer, M. E., \& Ariely, D. (2009). Too tired to tell the truth: Self-control resource depletion and dishonesty. Journal of experimental social psychology, 45(3), 594-597.

Miller, E. K., \& Cohen, J. D. (2001). An integrative theory of prefrontal cortex function. Annual Review of Neuroscience, 24, 167-202. doi: 10.1146/annurev.neuro.24.1.167

Paolacci, G., Chandler, J., \& Ipeirotis, P. G. (2010). Running Experiments on Amazon Mechanical Turk. Judgment and Decision Making, 5(5), 411-419.

Peysakhovich, A., \& Rand, D. G. (2013). Habits of Virtue: Creating Norms of Cooperation and Defection in the Laboratory. Available at SSRN: http://ssrn.com/abstract=2294242.

Pfeiffer, T., Tran, L., Krumme, C., \& Rand, D. G. (2012). The value of reputation. Journal of the Royal Society Interface, doi:10.1098/rsif.2012.0332.

Pitesa, M., Thau, S., \& Pillutla, M. M. (2013). Cognitive control and socially desirable behavior: The role of interpersonal impact. Organizational Behavior and Human Decision Processes, 122(2), 232-243.

Rand, D. G. (2012). The promise of Mechanical Turk: How online labor markets can help theorists run behavioral experiments. Journal of Theoretical Biology, 299, 172-179.

Rand, D. G., Greene, J. D., \& Nowak, M. A. (2012). Spontaneous giving and calculated greed. Nature, 489(7416), 427-430. 
Rand, D. G., \& Kraft-Todd, G. T. (2014). Reflection does not undermine self-interested prosociality. Frontiers in Behavioral Neuroscience, 8, 300. doi: 10.3389/fnbeh.2014.00300.

Rand, D. G., \& Nowak, M. A. (2013). Human Cooperation. Trends in Cognitive Sciences, 17(8), 413-425.

Rand, D. G., Peysakhovich, A., Kraft-Todd, G. T., Newman, G. E., Wurzbacher, O., Nowak, M. A., \& Green, J. D. (2014). Social Heuristics Shape Intuitive Cooperation. Nature Communications, 5, Article number: 3677.

Rand, D. G., Pfeiffer, T., Dreber, A., Sheketoff, R. W., Wernerfelt, N. C., \& Benkler, Y. (2009). Dynamic remodeling of in-group bias during the 2008 presidential election. Proc Natl Acad Sci US A, 106(15), 6187-6191. doi: 0811552106 [pii]; 10.1073/ pnas.0811552106

Roberts, M. J., \& Newton, E. J. (2001). Inspection times, the change task, and the rapid-response selection task. The Quarterly Journal of Experimental Psychology: Section A, 54(4), 1031-1048.

Roch, S. G., Lane, J. A. S., Samuelson, C. D., Allison, S. T., \& Dent, J. L. (2000). Cognitive Load and the Equality Heuristic: A Two-Stage Model of Resource Overconsumption in Small Groups. Organizational Behavior and Human Decision Processes, 83(2), 185-212. doi: 10.1006/obhd.2000.2915

Ruff, C. C., Ugazio, G., \& Fehr, E. (2013). Changing Social Norm Compliance with Noninvasive Brain Stimulation. Science, 342, 482-484.

Sanfey, A. G., Rilling, J. K., Aronson, J. A., Nystrom, L. E., \& Cohen, J. D. (2003). The Neural Basis of Economic DecisionMaking in the Ultimatum Game. Science, 300(5626), 1755-1758. doi: 10.1126/science. 1082976

Schulz, J. F., Fischbacher, U., Thöni, C., \& Utikal, V. (2014). Affect and fairness: Dictator games under cognitive load. Journal of Economic Psychology, 41, 77-87.

Shalvi, S., Eldar, O., \& Bereby-Meyer, Y. (2012). Honesty requires time (and lack of justifications). Psychological Science, 23, 1264-1270.

Sloman, S. A. (1996). The empirical case for two systems of reasoning. Psychological bulletin, 119(1), 3.

Stanovich, K. E., \& West, R. F. (1998). Individual Differences in Rational Thought. Journal of Experimental Psychology: General, 127(2), 161-188.

Suter, R. S., \& Hertwig, R. (2011). Time and moral judgment. Cognition, 119(3), 454-458.

Tajfel, H., Billig, R. P., \& Flament, C. (1971). Social categorization and intergroup behavior. European Journal of Social Psychology, 1(2), 149-178.

Tinghög, G., Andersson, D., Bonn, C., Böttiger, H., Josephson, C., Lundgren, G., . . . Johannesson, M. (2013). Intuition and cooperation reconsidered. Nature, 497(7452), E1-E2.
Van den Bos, K., Vermunt, R., \& Wilke, H. A. (1997). Procedural and distributive justice: What is fair depends more on what comes first than on what comes next. Journal of Personality and Social Psychology, 72(1), 95.

Vohs, K. D., Mead, N. L., \& Goode, M. R. (2006). The Psychological Consequences of Money. Science, 314(5802), 1154-1156. doi: 10.1126/science. 1132491

von Dawans, B., Fischbacher, U., Kirschbaum, C., Fehr, E., \& Heinrichs, M. (2012). The Social Dimension of Stress Reactivity: Acute Stress Increases Prosocial Behavior in Humans. Psychological Science, 23(6), 651-660. doi: 10.1177/ 0956797611431576

Whitt, S., \& Wilson, R. K. (2007). The Dictator Game, Fairness and Ethnicity in Postwar Bosnia. American Journal of Political Science, 51(3), 655-668.

Wright, P. (1974). The harassed decision maker: Time pressures, distractions, and the use of evidence. Journal of applied psychology, 59(5), 555.

Yamagishi, T., \& Mifune, N. (2008). Does Shared Group Membership Promote Altruism? Fear, Greed, and Reputation. Rationality and Society, 20(1), 5-30.

Zaki, J., \& Mitchell, J. P. (2011). Equitable decision making is associated with neural markers of intrinsic value. Proceedings of the National Academy of Sciences, 108(49), 19761-19766. doi: 10.1073/pnas.1112324108

Authors' biographies:

David Rand is an Assistant Professor of Psychology, Economics and Management at Yale University, and director of the Yale Human Cooperation Laboratory.

George Newman is an Assistant Professor at the Yale University School of Management.

Owen Wurzbacher is a Research Affiliate of the Yale Human Cooperation Laboratory.

Authors' addresses:

David Rand, Department of Psychology, Yale University, New Haven CT, USA.

George Newman, School of Management, Yale University, New Haven CT, USA.

Owen Wurzbacher, Department of Psychology, Yale University, New Haven CT, USA. 